\title{
DEVELOPING EDUCATIONAL ORGANIZATIONS WITH INNOVATION PEDAGOGY
}

\author{
Taru Penttilä \\ Dr., Turku University of Applied Sciences, FINLAND, taru.penttila@turkuamk.fi
}

\begin{abstract}
The needs of the working life and the competences required there are under a change, and educational institutions should be able to answer for this need by providing their students with competences needed. This usually requires changes in their own activities as well. The implementation of the change is often problematic even if the tools and methods how to conduct changes were familiar, because the change requires learning both on individual and organizational level, guiding of learning, internal training, and good command of communication and interaction. In this article we will discuss how to make the change - how to develop educational organizations with innovation pedagogy through the process consultation method. Innovation pedagogy is a learning approach focused on the development of innovation competences, defining how knowledge is assimilated, produced and used in a manner that can create innovations. Innovation pedagogy answers for the development needs of most educational organizations, but it is a challenging process to adapt and establish it and it requires that a change process is to be conducted in the organization. Process consultation is a development method for a work community where the personnel participates into the development of their own work, work processes and work community. Process consultation is maybe one of the most workable tools in the development of an expert organization in order to accomplish a real impact and change.

Educational organizations have an emerging need to answer for the demands of the changing world and working life, and innovation pedagogy, originating from the working life needs, answers directly for this demand. Organizations can be changed only 'from the inside' by involving the personnel into the implementation of the change, and therefore process consultation can be the tool for accomplishing the change. This article aims to provide new kind of methodological knowledge and tools, which have not earlier been studied and applied in this context. The process consulting methods can provide added value to develop pedagogical knowhow in educational organizations and thus support their internal learning and development. The theoretical framework of the article is put into practice in the description of a real empirical case. The focus in this article will be in higher educational organizations, but the approach is applicable for all level of educational institutions. The managerial outcome of the paper is that in the development of an educational organization process consultation can be most powerful tool in order to conduct a real change and impact.
\end{abstract}

Keywords: Educational organizations, innovation pedagogy, innovation competence, process consultation, change 


\section{BACKGROUND, OBJECTIVES AND METHODS}

Ongoing changes, coping with workload, development of knowledge and competences at work, are challenges almost in every company and other organizations currently, regardless the size or business field of the organization. The needs of the working life and the competences required there are under a change, and educational institutions should be able to answer for this need by providing their students with competences needed. This usually requires changes in their own activities as well. In addition to substance knowledge there is a need for customer-centred thinking, creativity, interaction skills, tolerance for uncertainty and difference. Individual expertise needs to develop to communal/interpersonal expertize when the working life is getting more complicated. The implementation of the change is often problematic even if the tools and methods how to conduct changes were familiar, because the change requires learning both on individual and organizational level, guiding of learning, internal training, and good command of communication and interaction.

Innovation pedagogy is a strategic approach to learning, which has not yet been widely utilized outside the higher educational sector although it can offer many tools to meet above mentioned challenges. In addition to the central role of the learner, innovation pedagogy promotes practical activities as well as creating, constructing and cumulating knowledge. Scientific knowledge facilitates solving practical problems, but sometimes a new practice born out of immediate need in a practically oriented situation results in a scientific breakthrough. Through collaborative learning, different actors are able to work together in dialogue in such a manner that their own expertise can be efficiently shared and combined in novel ways resulting in something more than the sum of its parts. The success of the communities is based on know-how and sharing knowledge as well as on the ability to combine different points of view and approaches. Innovations are more frequently generated where different fields of expertise meet. In brief, innovation pedagogy is a learning approach focused on the development of innovation competences, defining how knowledge is assimilated, produced and used in a manner that can create innovations. Here innovation activities are understood as processes of constantly improving expertise, which lead to new sustainable ideas, further expertise or novel practices applicable in working life. Innovation pedagogy answers for the education development needs of most educational organizations, but it is a challenging process to adapt and establish it and it requires that a change process is to be conducted in the organization.

Process consultation is a development method for a work community where the personnel participates into the development of their own work, work processes and work community. As a method it emphasizes the client's responsibility and role in the development process. All these elements have a positive impact on the client's experience that he/she really owns the process. This adds the client's commitment to the facts that are essential for the process to success; decision-making and activities. By involving the employees in the development stage and giving them real power and status, they will remarkably commit to the implementation. Process consultation is maybe one of the most workable tools in the development of an expert organization in order to accomplish a real impact and change.

Educational organizations have an emerging need to answer for the demands of the changing world and working life, and innovation pedagogy, originating from the working life needs, answers directly for this demand. Organizations can be changed only 'from the inside' by involving the personnel into the implementation of the change, and therefore process consultation can be the tool for accomplishing the change. In other words, combining the methods and tools of innovation pedagogy (concerning especially change and learning in organizations) to the process consulting methods is a new and innovative approach and can offer new solutions for the development of educational organizations. This applied and pragmatic approach can help in developing learning organizations operating successfully in changing working life.

This article aims to provide new kind of methodological knowledge and tools, which have not earlier been studied and applied in this context. In addition to the new mixed method approach, the process consulting methods can provide added value to develop pedagogical knowhow in organizations and thus support their internal learning and development. In other words, successful implementation of innovation pedagogy can take place with help of process consulting, and therefore the focus of the theoretical framework is put on these both. The theoretical framework of the article is put into practice in the description of a real empirical case. The focus in this article will be in higher educational organizations, but the approach is applicable and useful for all level of educational institutions, as well as for all expert organizations including different kind of companies. The choice of the empirical material origins from the author's experience as a process consultant in the mentioned one (in all stages of the process) and similar kind of development processes. 


\section{INNOVATION PEDAGOGY - A STRATEGIC LEARNING APPROACH FOR EDUCATIONAL ORGANIZATIONS}

The operational environments of educational institutions all around the world are under constant change. However, educational institutions, especially in higher education, still tend to educate students with traditional methods originally designed for a world that is stable and mainly emphasizes the learning of explicit knowledge. Methods better suited for a constantly changing world focus on activating students in learning and also include unofficial situations and contexts.

In all areas of knowledge creation, demand for a broader perspective is increasing. We are facing issues and challenges in creating added value needed to maintain our level of welfare, challenges which are becoming increasingly difficult to address within the framework of a single method, be that a discipline or a profession. At the same time, we are very well aware of the fact that knowledge is at the heart of innovation and that innovation typically emerges at the boundaries of different knowledge domains. The economy and the success of future enterprises is more and more based on innovations, which are created by innovative employees capable of not only inventing something new by themselves, but also of participating in the processes where new solutions are created by working together. The core idea of innovation pedagogy is to bridge the gap between the educational context and working life. Learning and teaching processes are to be developed so that they provide improved competences for the students and enable personal and professional growth. Learning is deeper when previously-gained knowledge is continuously applied to practical contexts. Creating new services, products and organizational or social innovations - new added value - requires both knowledge and skills, which are applied to an innovation process. (Gibbons et al. 1994; Kairisto-Mertanen et al. 2010; Nonaka \& Takeuchi 1995; Nowothy \& Gibbons 2001; Nowothy \& Gibbons 2003.)

The core of innovation pedagogy lies in emphasizing interactive dialogue between the educational organization and students as well as the surrounding working life and society. Accordingly, its conceptual core can be divided, as Figure 1 describes, into three different spheres in parallel to the three major actor groups benefiting from innovation pedagogy (Penttilä et al. 2011a; Penttilä et al. 2013; Penttilä 2014):

- final learning outcomes, creation of innovations and produced capability to participate in diverse innovation processes - having primarily to do with students, who are expected to create innovations while affiliating with working life

- learning of innovation competences alongside with study programme specific knowledge, skills and attitudes - being mostly connected with working life, which provides students with ideal surroundings to acquire the competences needed in innovation processes and in future working life in general

- meta-innovations - referring to the necessary cornerstones needed for learning according to innovation pedagogy; the elements enabling innovation pedagogy to be applied, including methods of learning and teaching utilized in the learning processes by the faculty members together with the students enhancing both the creation of innovations and innovation competences.

Meta-innovations are essential requirements for innovation pedagogy to succeed, as they enable the emergence of the so-called cornerstones of innovation pedagogy in any learning environment. These cornerstones include innovative learning and teaching methods, cross-disciplinary learning environment (boundary crossing), integrated and extensive research and development activities, flexible curricula, concentration of acknowledging the importance of entrepreneurship and service production as well as internationalization in the level of research, development and student engagement. Meta-innovations contribute especially to the development or student's interpersonal and networking competences. 


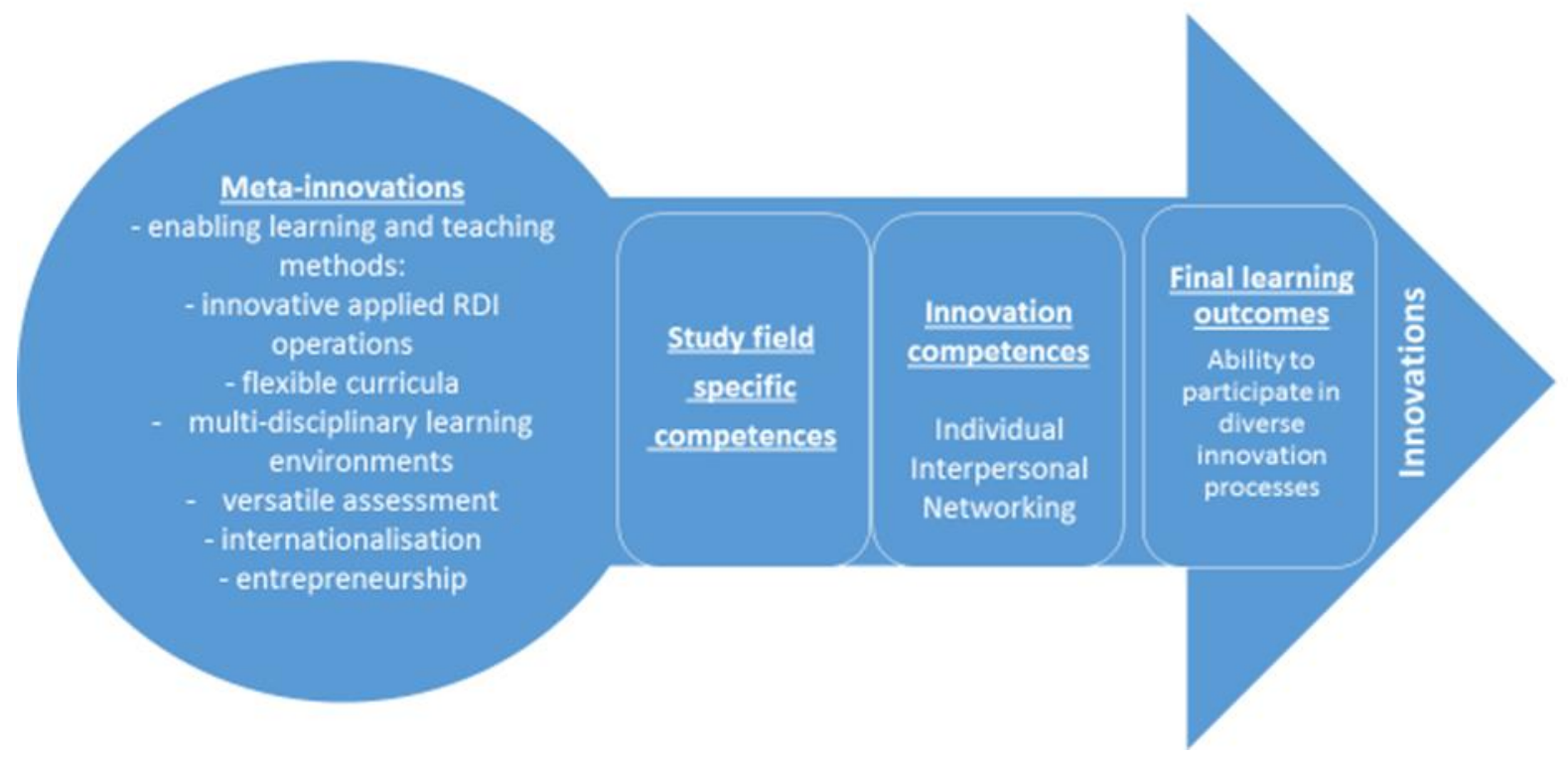

FIGURE 1 Innovation pedagogy in the nutshell

Innovation pedagogy is a strategic choice, which requires understanding and agreement on setting said goals. It represents a philosophy that permeates through the entire organization, and is visible in all activities. Innovation pedagogy offers a name to the development of students' competences, enabling them to participate in the processes of creating innovations. Even though these competences are different from the traditional ones, it does not mean that the old study programme specific competences should be abandoned. However, we cannot leave students to cope by themselves without having put special emphasis also on equipping them with all the essential tools for the future. In innovation pedagogy, innovation competences represent a new sphere of know-how. By cultivating research and development activities in multidisciplinary environments we can make a significant contribution to the creation of regional, local and international innovations.

\section{IMPLEMENTING CHANGE IN EDUCATIONAL ORGANIZATIONS}

Developing organizations, including educational organizations, usually means that more or less changes are needed. Applying and implementing innovation pedagogy in educational organizations means that there are means and tools to develop the organization, but in order to apply them there is a need for changes in processes and in ways of action. Schein (1987) emphasizes that change is a process that can be broken down into logical stages and that different mechanisms of change have to be managed at these stages. At the first stage, unfreezing, the key is to provide disconfirming information, link it to important personal goals or ideals so that guilt or anxiety will be felt, and simultaneously provide enough psychological safety so that the disconfirming information will be attended to instead of denied. If through these mechanisms the target group/ customer has become motivated to unlearn something and replace it with new learning, they/ he/she will do so either by the mechanism of identifying with a new role model or by scanning the environment for information most relevant to the problem. The actual change can then be thought of as a cognitive restructuring or redefinition of the problem that leads to new perceptions, new judgements, and ultimately new behaviours. The change process will be completed when these new responses are tested for fit with the rest of the self-concept and personality, and within the customer's relationships. Only when the new responses begin to be confirmed by important others we can say that the change has really been stabilized. (Schein 1987, 113-114; Schein 2001, 131-156)

Also Valpola (2011) describes the change process with different stages. There are five elements/stages needed for the successful change process: Definition of the need for the change, creation of common 
understanding and objective, ability for change, first actions, and anchoring to the practice. If any of the elements is missing, the change process will fail. (Valpola 2011)

Conducting changes in organizations across cultural boundaries is challenging, and especially if the actors in the change management process are not familiar with the cultures that are involved. Constraints imposed by the cultural rules must be recognized and understood. Even the definition of what is helpful/ what can and should be developed, is often culturally determined, and therefore a good deal about the culture where operating must be known well enough. The essential dilemma in helping/ consulting is how to conduct change in the customer's systems without people losing face, i.e. how a customer / target group can be gotten to see new perspectives and to consider new alternatives without being made to feel that that their present mode is somehow bad or failed (Schein 1985; 1987)

Process thinking is an approach which can be the key to organizational development challenges. It answers the questions how to help people to make changes, how people get committed to the changes and how an organization can learn to conduct changes. It aims to create opportunities for planning and implementing changes, and therefore process consultation forms often a practical framework for organizational development.

\section{PROCESS CONSULTATION}

The main argument for process consulting is to help people in organizations to help themselves, i.e. the consultant working with and not for the client is a keynote of the process consultation philosophy. Process consultation is an organizational development method where the personnel participates in the development of their own work processes and work community. As a method it emphasizes the responsibility and role of the customer in the development process. These elements have a positive impact on the customer's sensation that he/she really owns the process. This increases the customer's commitment to the issues relevant for success; decision-making and actions. When employees are involved in the development process and they are given also decision-making power, their commitment to the implementation is increased essentially.

Process consultation is generally contrasted with expert consultation and is frequently seen by its advocates as a superior style of management consulting. In practice, however, almost all management consulting involves a mix of expert and process models, with the consultant frequently shifting roles to meet the needs of the situation. Be this as it may, process consultation certainly has many strengths. As compared to experts who bring packaged solutions that may have general validity, but in fact are not the best prescription for the organization, process consultation has the powerful advantage of being by its nature specifically tailored to the specific situation.

The process consultation can be divided in several stages, where the first is the first contact with the potential customer. The aim is to find out if the consultant has opportunities to help the customer, and on the other hand, whether the customer can really benefit from the consultation. Next, the consulting relationship is to be defined (e.g. expectations, direct and indirect customer roles) and outlined (e.g. objectives, timetable), and the working methods are settled. Insights into 'what really goes on' are needed next at the stage of information gathering and diagnosis. There are lots of different diagnosis models but it does not mean that there must always be a diagnosis period followed by an intervention period because in reality intervention begins in the first customer contact. Everything a consultant does from the moment the customer makes the contact with the consultant is an intervention of some sort, and therefore it is appropriate to emphasize intervention as central. There is no diagnosis period prior to intervention though many consultation models present it as such. However, diagnosis models can help to anticipate and decipher the situation, but it is good to keep in mind that both diagnosis and intervention are both instantaneous and perpetual processes. Finally, there is the stage of closing the consultation process including the evaluation of the process. (Teivonen 2008; Schein 1987)

Which intervention is most appropriate depends on many things, e.g. on the stage of the consultation process (for example new customer or familiar organization) or the customer setting (e.g. one-to-one relationship/ group setting/ larger organizational setting). There are several models of the possibilities what kind of interventions to consider. Schein differentiates a situation's content from its process and its structure, and second whether to focus on the task issues, interpersonal issues or group setting. According to Schein, it is often useful to observe interpersonal functions, but primarily the interventions should focus on task issues (basic tasks and objectives in work/ content; problem-solving and decision-making/ process; and work processes and modes, division of responsibilities/ structure). Customers are often pretty sensitive to the 
content issues more than to process and structure, and helping customers to see data on process and structure on their own in the future is most likely to be helpful.(Schein 1987, 1999; Honkanen 2006).

The interventions must be guided by the assumptions underlying the helping process. The consultant has to act consistently with these assumptions, which means to help the customer to own his own problems, to maintain his own initiative and to help him to make his own diagnosis and select his own interventions. The tools a consultant can use here are e.g. inquiry, diagnostic questions in order to stimulate the customer's own diagnostic thinking, and action alternative interventions that begin to give ideas what the customer might do. (Kykyri 2008; Schein 1987)

Goal-oriented process consultation means that the goal is achievable and its achievement can be evaluated. Thus every process consultation should also include the feedback about the process and the evaluation of the results. (E.g. Kurpius et al 1993; Honkanen 2006)

\section{PROCESS CONSULTATION IN ACTION IN INTERNATIONAL CONTEXT - A CASE STUDY EXAMPLE}

In following, the theoretical framework is described in practice with an authentic case study. The consulting party here is Turku University of Applied Sciences (TUAS) where the consultant and the supporting consultation team came from Innovation Pedagogy research group. The customer was a big European higher education institution (near 30000 students; TUAS 10000 students). The development process took place in 2014 and its duration was one year. Both universities have many different faculties, but TUAS differs from traditional universities in that the faculties are multidisciplinary.

\section{Preparation}

The first contact leading to the development process came from the customer's initiative. There had been some co-operation activities between the institutions earlier and the customer had been impressed about innovation pedagogy implemented at TUAS. After approval of financial arrangements the customer suggested that an agreement on the development process could be made. The main objective of the agreement focused the pedagogical development of the customer organization including application of innovation pedagogy philosophy and methods. Because of the huge size of the organization and scarce resources, the participants were outlined to specific faculties. The individuals participating were named and their roles were defined. The working methods were decided including e.g. consultation, tutorials, and work counselling and collaborative seminars implemented with innovation pedagogy methods. The consultation methods emphasized especially interviews, observations, one-to-one and group discussions.

Information gathering and diagnosis were started, in addition to discussions with customer/assigning party, with a situation analysis with the participants, where they described their thoughts and needs concerning the current situation. This diagnosis/analysis stage was for creating a roadmap for development and conducted by the participants. However, it has to be stated that actually the diagnosis stage took place during the whole development process. Problem definition and solution searching are more or less interconnected, the problems to be defined when the objectives are compared with the current situation. In addition in a longer consultation process the diagnostic work is needed during the whole process e.g. after each intervention.

\section{Diagnosis}

The diagnostic stage and information gathering is especially demanding in international context and therefore cultural sensitivity cannot be emphasized enough. It is easily assumed European cultures to be mentally close to each other, but the differences can be huge. In this case especially somehow unequal understanding about power distance (superior/ subordinate relationships; e.g. Hofstede 2010), decisionmaking systems and bureaucracy lead to administrative work requiring more time than expected.

The diagnostic stage in the beginning showed up the situation in the organization concerning the change process. The stage of unfreezing had already taken place, there was anxiety concerning the current situation and the participants were motivated to unlearn something and replace it with new learning. The customer had also scanned the environment for information most relevant to the problem and thus ended up to contact TUAS. Innovation pedagogy seemed to offer solutions how to develop the organization.

\section{Interventions}

The interventions during the development period were numerous and mostly focused on task issues on content, processes and structure. The content was emphasized especially during the first half of the development process. The participants were working with the questions: What is innovation pedagogy? How 
is it implemented at TUAS? How and if it can be applied at own institution? The reflection on this working period indicated that cognitive restructuring or redefinition of the problem took place and led to some new perceptions and judgements. It led also to the need and will to ultimately new behaviours, which generated the focus shift from content to processes and structures. The established work processes and procedures were questioned and compensated with some new, which demonstrated that the changes in content stay minor and have not a special impact on organizational development if processes and structures are not developed. The issues during the second half were therefore more on changes needed in processes, e.g. team work and responsibilities, interaction/dialogue forums crossing borders (faculties and disciplines), cooperation models on all levels, supporting quality systems and guidelines and motivation systems. The essential issues on structure development came up too, such as that strategic decision-making is needed, i.e. support and commitment of the management, as well as structural changes on practical implementation such as curriculum development and student counselling.

\section{Evaluation}

The evaluation stage took place during the whole process, i.e. there was diagnostic, formative and summative evaluation done during the process, which helped in reacting quickly to upcoming questions and supported targeting of new interventions. It was stated earlier that the change process will be completed when new responses are tested for fit with the rest of the self-concept and personality, and within the customer's relationships. In the final feedback the participants brought up that the development process had given support and encouragement for own thoughts to which direction university pedagogy should be developed. The process had provided practical ideas to the implementation. However, the main problem was that the most of participants felt their possibilities to put new pedagogical ideas to practice are limited because the structures and processes are not developed simultaneously enough. Because of the huge size of the institution the changes in processes and structures will take years. However, the participants appreciated highly the support provided for their work by the development process. It was emphasized that the process had had impact especially on the working culture by bringing representatives of different disciplines together to work towards shared objectives, which is experienced as a new way of action encouraging collaboration.

Open discussion, sharing experiences and learning from others were mentioned as the most fruitful methods used. According to Schein (2001), organizational culture can be divided into three levels: in artefacts which are visual organizational structures and processes; in espoused values such as strategies and goals and in basic underlying assumptions which are taken as granted beliefs, unconscious perceptions and feelings and thoughts. When the culture is seen like that it is quite sure that the change cannot take place without resistance. The experiences about resistance and problems at TUAS, when innovation pedagogy was launched there, were seen as very useful and familiar in the customer' own organization. For example, at TUAS, the artefacts which were questioned first were the ways how people worked. The teaching profession has traditionally been very independent requiring only individual input. Innovation pedagogy challenges the individual way of working and instead emphasizes the importance of interaction and networking among faculty members, students and the surrounding economy. The new way of doing things was experienced first as a threat among many faculty members. The espoused values concerned mostly producing graduates of good quality which meant earlier that the teacher had to provide all necessary information in the class-room. Learning was understood to taken place during a lecture if the subject matter was lectured profoundly. When introducing the innovation pedagogy approach and culture the basic assumptions of the faculty members were taken under consideration. The most important thing in the beginning was to create forums where people could meet and learn to know each other. There must be space for criticism but there must be space for innovative and solution oriented thinking as well. The faculty members were encouraged to get acquainted with other faculty members unfamiliar to them. The resistance decreased gradually. This kind of examples and open discussion helped in how to conduct change in the customer's systems without people losing face, i.e. how a target can be gotten to see new perspectives and to consider new alternatives without being made to feel that that they are the only ones having such problems.

\section{CONCLUSIONS}

Innovation pedagogy can provide both a strategic approach as well as methods and tools (meta-innovations in Figure 1) how to develop an educational organization. It defines goals and objectives and ways of working how to achieve them. What actually makes innovation pedagogy a strategic issue? A university must not operate alone making decisions without a regular and systematic dialogue with its interest groups and the surrounding environment. There are a number of requirements set to the university by its different interest groups. As an outcome of this dialogue, a set of strategic decisions must be made. Basic decisions are 
made on organizational strategy level concerning the overall purpose and scope of an educational organization and how it can contribute to its environment by adding value, but also on operational strategy level concerning separate organizational functions such as e.g. teaching and learning methods applied. Operational strategy level is not to be neglected because it is concerned how the component parts of an organization deliver effectively the organizational level strategy in terms of resources, processes and people. Thus, if innovation pedagogy begins with real commitment on the part of the whole organization it can become a real cross-disciplinary approach utilizing all its potential and it is possible to design strategies that are holistic rather than piecemeal. (Penttilä et al. 2011b) Too often a strategy is described as a 'from top to down' activity, the management defining the goals and action plans which the employees will implement in their every-day work. A successful strategy process starts from collaboration with the employees in strategy planning, and its implementation is measured on daily basis in the encounters of employees and customers.

Collaboration is in the core of process consultation. The employees participate into the development of their own work processes and the working community. The commitment to the development can be increased essentially by taking the employees along to the development process from the first start and given them an active role and real decision-making power. The case example indicates that innovation pedagogy can be used for the development of educational organizations with the methods of process consulting but the objectives must be realistic and applicable in the specific cultural context. Innovation pedagogy tools can develop an organization's working methods and practices but a more holistic and sustainable change requires intervening also processes and structures. Concerning to the case example and referring to Valpola's model cited earlier, the further development will depend a lot whether the anchoring of the actions to the practices and processes will be conducted; if not there will be disappointment and cynicism especially among the participants of the development process. However, in the development of an educational organization process consultation can be most powerful tool in order to conduct a real change and impact. Process consulting can improve the customer's own performance and initiative on a sustainable basis, and therefore the bigger the needed change is, the more process consulting can help the customer.

\section{REFERENCE LIST}

Gibbons M., Limoges C., Nowotny H., Schwartzman S., Scott P. \& Trow, M. (1994). The New Production of Knowledge. The dynamics of science and research in contemporary societies. London: Sage.

Hofstede G., Hofstede G. J., Minkov M. (2010). Cultures and Organizations: Software of the Mind, 3rd ed. New York: McGraw-Hill.

Honkanen H. (2006). Muutoksen agentit. Helsinki: Edita.

Kairisto-Mertanen, L., Penttilä, T., Putkonen, A. (2010). Embedding innovation skills in learning. In Innovation and Entrepreneurship in Universities (ed. Neuvonen-Rauhala M-L). Series C Articles, reports and other current publications, part 72. Lahti University of Applied Sciences.

Kurpius D. J., Fuqua D. R., Rozecki T. (1993). The Consulting Process: A Multidimensional Approach. In Journal of Counselling and Development July-August 1993, Volume 71, pp. 601-606.

Kykyri V-L. (2008). Helping Clients to help themselves. A Discursive Perspective to Process Consulting Practices in Multi-party Settings. Academic Dissertation. Jyväskylä: University of Jyväskylä.

Nonaka I. \& Takeuchi H. (1995). The Knowledge Creating Company: How Japanese Companies Create the Dynamics of Innovation. New York: Oxford University Press.

Nowotny, H., Scott, P. \& Gibbons, M. (2001). Re-Thinking Science. Knowledge and the public in an age of Uncertainty. London: Polity Press.

Nowotny, H. \& Scott, P. \& Gibbons, M. (2003). 'Mode 2' Revisited: The new production of knowledge. Minerva 41(3) pp.179-194.

Penttilä T. (2014). Innovation pedagogy - Pedagogia de Innovación. Presentation at III Peruvian-Nordic Education Forum. Lima, Peru, 21.10.2014

Penttilä, T., Kairisto-Mertanen, L. \& Putkonen, A. (2011a). Communicational Aspects of Innovation Pedagogy and Stakeholder Dialogue. In Towards Innovation pedagogy - A new approach to teaching and learning in universities of applied sciences (eds. A. Lehto, L. Kairisto-Mertanen \& T. Penttilä) Reports from Turku University of Applied Sciences. 100, pp. 65-77. Turku: Turku University of Applied Sciences. 
Penttilä T. - Kairisto-Mertanen L. - Putkonen A. (2011b). Innovation pedagogical approach - strategic viewpoints. Proceedings of International Conference of Technology, Education and Development (INTED2011)

Penttilä T. - Kairisto-Mertanen L. -Putkonen A. - Lehto A. (2013). Innovation Pedagogy - A Strategic Learning Approach for the Future. In Lehto A. -Penttilä T. (eds.) Pedagogical views on innovation competences and entrepreneurship, pp.11-23. Reports from Turku University of Applied Sciences 171. Tampere 2013.

Schein E. H. (2001). Yrityskulttuuri. Selviytymisopas. Helsinki: Suomen Laatukeskus Koulutuspalvelut Oy.

Schein E. H. (1999). Process consultation Revised. Reading: Addison -Wesley.

Schein E. H. (1987). Process consultation. Volume II. USA: Addison-Wesley.

Schein E. H. (1985). Organizational culture and leadership. San Francisco: Jossey-Bass.

Teivonen T. (2008). Työnohjaajan ja prosessikonsultin roolit. In 'Työnohjaus - mitä, missä, milloin?', ed. Keskinen S. pp. 153-178. Täydennyskoulutuskeskuksen julkaisuja B 23.

Valpola A. (2011). Muutoksen johtaminen. Opetusalan johtamisen foorumi 10.6.2011. www.oph.fi/download/133176_Valpola_Anneli.pd 